\title{
E1 liberalismo deontológico vuelve a la vida (y mucho antes de lo pensado)
}

\author{
Deontological Liberalism Back to Life \\ (Much Earlier Than Thought)
}

Julio Montero*

Recepción y evaluación de propuesta: 20/2/2014

Aceptación: 20/03/2014

Recepción y aceptación final: 22/6/2015

Resumen: En su artículo "Legalismo moral y tolerancia: crónica de una muerte anunciada" publicado en este mismo volumen de Discusiones, René González de la Vega sostiene que el liberalismo deontológico es filosóficamente incoherente con la virtud política de la tolerancia. En esta discusión trato de mostrar que René se equivoca. Mi argumento será que una versión arquetípica del liberalismo deontológico, como el liberalismo político de John Rawls, no solamente es compatible con la tolerancia sino que además le reconoce a esta un papel privilegiado. Finalmente, sugeriré que, contrariamente a lo que René sostiene, variantes más comprensivas de liberalismo solo pueden darle a la tolerancia una importancia secundaria.

Palabras Clave: Liberalismo político, liberalismo comprensivo, convicciones morales, cultura pública política, John Rawls.

* CONICET / UBA / Grupo de Filosofía Política), Argentina.

E-mail: jmnormandia@gmail.com. 


\begin{abstract}
In his article "Moral legalism and tolerance: Chronicle of a Death Foretold" published in this volume of Discusiones, René Gonzalez de la Vega argues that deontological liberalism is philosophically inconsistent with the political virtue of tolerance. In this comments I try to show that René is wrong. My argument will be that an archetypal version of deontological liberalism as the political liberalism of John Rawls is not only compatible with tolerance but that also it recognizes the latter a privileged role. Finally, I will suggest that, contrary to what René holds, more comprehensive versions of liberalism can only give tolerance a secondary importance.
\end{abstract}

Key words: Political liberalism, comprehensive liberalism, moral convictions, political public culture, John Rawls.

\title{
I. Introducción
}

Una de las principales virtudes de la tradición liberal es, sin duda, su capacidad reflexiva y autocrítica. De hecho, desde su surgimiento mismo en los albores del mundo moderno, el liberalismo no ha dejado de revisarse y de cambiar. La fascinación de los liberales primitivos con la autopropiedad, las libertades económicas y la tolerancia religiosa cedió rápidamente protagonismo ante preocupaciones más generales vinculadas a la autonomía, la independencia moral y la igualdad política. Más tarde, la distribución de la riqueza y la integración multicultural se volvieron predominantes en los debates entre liberales, y ya en este siglo el liberalismo ha comenzado una indagación sobre la naturaleza cosmopolita de la justicia de consecuencias teóricas imposibles de prever. Tal vez por esta capacidad reflexiva que lo impulsa a mutar, no deberíamos hablar de liberalismo a secas sino más bien de liberalismos: el liberalismo político, el liberalismo de la autonomía, el liberalismo clásico, el liberalismo multicultural, el liberalismo igualitario, el liberalismo cosmopolita y varios más ${ }^{1}$.

1 Para un panorama bastante completo de las diversas perspectivas que conviven dentro de la filosofía liberal, puede consultarse Gaus, G., Courtland, J., y Schmidtz, D., "Liberalism", en The Stanford Encyclopedia of Philosophy, 2015, http://plato.stanford.edu/archives/spr2015/entries/liberalism/. 
El liberalismo deontológico vuelve a la vida (y mucho antes de lo pensado)

El artículo "Legalismo moral y tolerancia: crónica de una muerte anunciada" de René González de la Vega rinde tributo a esta actitud de constante autocrítica del pensamiento liberal, explorando con gran rigor argumentativo la capacidad de esta tradición de acomodar consistentemente una de las grandes virtudes políticas, a saber, la virtud de la tolerancia. De acuerdo con René, el liberalismo deontológico, que se ha vuelto popular en el mundo anglosajón tras la publicación de Una teoría de la justicia de John Rawls, presupone una forma de razonamiento moral que vuelve a la tolerancia o bien irrelevante $o$ bien recalcitrante ${ }^{2}$. Si este diagnóstico es acertado, podríamos tener razones para preferir un liberalismo no deontológico o incluso para abandonar la ancha avenida del pensamiento liberal.

En esta breve discusión voy a tratar de mostrar que René se equivoca. No solamente porque el liberalismo deontológico puede acomodar la virtud de la tolerancia, sino además porque puede darle una preponderancia que ninguna otra variante de liberalismo le concedería. Voy a empezar reconstruyendo rápidamente el interesante argumento de René. Después de eso, intentaré exponer algunas de las ideas principales del liberalismo político de Rawls para explicar por qué hay buenas razones para pensar que al menos esta variante de liberalismo deontológico puede dar a la tolerancia un lugar central en el panteón de las virtudes morales. Finalmente - y solo para disparar la polémica- me permitiré sugerir, casi a modo exploratorio, que un liberalismo comprensivo más integrado que no distinga tajantemente entre lo justo y lo bueno solo podría reconocerle a la tolerancia un papel de reparto entre las virtudes políticas.

\section{II.El liberalismo deontológico y la cuadratura del círculo}

Como todos los grandes argumentos, el de René se puede esquematizar sin problemas. La primera premisa del argumento es que tolerar algo supone dejar sin efecto alguna creencia que, sin embargo, seguimos considerando crucial. Supongamos, por ejemplo, que usted pen-

2 Rawls, J., A Theory of Justice, Cambridge, Mass., Belknap Press, 2005. 
sara que la música de rock es un ruido insoportable, carente de todo valor estético. Y supongamos que, para su desgracia, su hija adolescente se uniera a una banda de rock y practicara todos los días en el living de su casa. Si, a pesar de su profundo desprecio por el rock usted le permitiera a su hija seguir adelante con los ensayos, estaría poniendo en práctica la tolerancia ya que dejaría sin efecto una creencia que usted seguiría considerando completamente verdadera. La tolerancia supone así, (a) la existencia de un acto, práctica o comportamiento que desaprobamos; (b) la capacidad o competencia real para impedir u obstaculizar su realización; y (c) la decisión de permitir su realización a pesar de todo ${ }^{3}$. En consecuencia, como bien apunta René, la tolerancia no puede basarse nunca en la indiferencia o la asimilación del comportamiento tolerado. Para que podamos hablar realmente de tolerancia es fundamental que el comportamiento que consentimos nos resulte realmente disvalioso y hasta ofensivo ${ }^{4}$. Por eso, la tolerancia supone siempre un desgarramiento interno del sujeto que tolera, un desgarramiento que desgaja su conducta de las convicciones que lo definen como la persona que es.

La segunda premisa es que el razonamiento liberal deontológico inevitablemente distingue entre dos clases de razones para actuar: razones morales y razones de otra clase (éticas, religiosas, estéticas, etc.). Mientras que las razones morales son por definición universales y aspiran a tener validez interpersonal, las razones de otra clase, incluidas las éticas, serían de carácter puramente personal. En otras palabras, serían razones válidas para usted en virtud de los libros que leyó, las tradiciones en las que creció o las cosas que le pasaron durante su vida, pero no tendrían por qué ser válidas para su vecino.

${ }^{3}$ Existe consenso entre varios autores importantes respecto de que la tolerancia supone estas tres condiciones. Véase, por ejemplo, Forst, R., "Toleration", en The Stanford Encyclopedia of Philosophy, 2012, http:// plato.stanford.edu/archives/sum2012/entriesoleration/; Nicholson, P., "Toleration as a moral ideal" en Horton, J. y Mendus, S. (eds), Aspects of Toleration, Londres/Nueva York, Routledge, 2013, pág. 160.

${ }^{4}$ Williams, B., "Toleration: an impossible virtue", en Heyd, David (ed.), Toleration: An Elusive Virtue, Princeton, Princeton University Press, 1998, pág. 25. 
El liberalismo deontológico vuelve a la vida (y mucho antes de lo pensado)

La tercera premisa sostiene que cuando un liberal deontológico enfrenta la disyuntiva de tolerar o no una creencia que desaprueba, siempre debe resolver el problema por referencia a razones morales. De hecho, René está convencido de que ningún valor que no pertenezca al ámbito de la moralidad tiene posibilidades de ser tolerado por un liberal deontológico. Esto se debe a que, para un liberal deontológico, las normas morales derrotan automáticamente a todas las demás. Así, si usted pensara, por ejemplo, que hay razones morales y no meramente estéticas para combatir la música de rock, la carrera artística de su hija estaría irremediablemente terminada.

La cuarta premisa del argumento asevera que cuando se presenta un conflicto entre dos principios morales opuestos, dadas sus exigencias de completitud y consistencia, el liberalismo deontológico solo admite dos posibilidades: o bien las personas que incurren en el comportamiento desaprobado tienen un derecho a hacer lo que hacen y hay una obligación de no impedírselo; o bien, por el contrario, ese derecho no existe y las razones que podría haber para tolerar la conducta cuestionada se desvanecen. En el primer caso, no hay nada que tolerar: el comportamiento que desaprobamos es un comportamiento moralmente admitido y la regla que podría justificar la intolerancia queda eliminada del sistema normativo. En el segundo caso, por el contrario, el comportamiento que desaprobamos está moralmente prohibido y estamos plenamente autorizados a obstaculizarlo. René expresa el punto con estas palabras:

...Si la objeción inicial está basada en nuestras concepciones éticas (o religiosas) personales, la aceptación o el rechazo deben estar basados en una consideración moral que pueda ser universalmente aceptada. Cuando las consideraciones contenidas en la objeción resultan ser suficientes para emitir un juicio ético negativo, pero no suficientes para emitir un juicio moral negativo, es cuando debe ejercitarse la tolerancia; es decir, no intervenir en contra del acto que generó dicha objeción. Es en estos casos cuando uno debe darse cuenta que nuestras consideraciones éticas no son suficientes para justificar un reclamo generalizado sobre ciertas prácticas individuales. Ahora bien, 
si las razones éticas son suficientes para emitir un juicio moral negativo, entonces no hay acto que se daba tolerar y nuestra obligación es actuar conforme a la valoración moral.

La conclusión del argumento se sigue con toda naturalidad: si la tolerancia supone por definición dejar sin efecto una creencia que consideramos fundamental, el liberalismo deontológico no deja ningún espacio para ella, ya que siempre suprime alguna de las creencias en pugna. En el mejor de los casos, cuando el liberalismo deontológico tropieza con dos valores de peso igual, la tolerancia se vuelve recalcitrante en el sentido de que no aporta ninguna solución. Por esta razón, René sostiene que la tolerancia no cumple ningún papel importante para el liberalismo deonotológico. Lejos de ser una virtud o disposición deliberativa que nos ayuda a identificar situaciones en las que debemos abstenernos de actuar en base a razones que seguimos considerando como fundamentales, opera como un dispositivo que depura nuestro sistema normativo, descartando principios, valores o normas mutuamente inconsistentes. Así, el liberalismo deontológico sería propenso a convalidar la indiferencia ética o a fomentar la imposición de la moral.

No hace falta decir que si esta conclusión es acertada, hablar de tolerancia en el marco del liberalismo deontológico sería como hablar de la cuadratura del círculo: una completa imposibilidad conceptual.

\section{El liberalismo deontológico resurge de sus cenizas}

La primera pregunta que podríamos hacernos para dar inicio a la discusión es esta: aun si René tiene razón y el liberalismo deontológico no deja ningún lugar significativo para la tolerancia, ¿sería esto realmente un problema? Después de todo, la tolerancia es una virtud diseñada para poner coto a sistemas de pensamiento autoritarios que aspiran a colonizar la vida de quienes no suscriben su punto de vista. Pero el liberalismo ya supone un compromiso con el derecho de toda persona a vivir de acuerdo con su propia concepción de lo que vale la pena y a promover su visión ética del mundo aunque otros la con- 
El liberalismo deontológico vuelve a la vida (y mucho antes de lo pensado)

sideren errada, ofensiva o despreciable. Por consiguiente, tal vez podría prescindir del remedio de la tolerancia. Podría prescindir de ese remedio porque no sufre de la enfermedad que el remedio cura. Para ser honesto, lo verdaderamente importante no es sentir ese desgarramiento que se produce cuando decidimos no poner en acción ciertas creencias que vemos como fundamentales, sino vivir en un mundo en el que cada uno pueda seguir su camino siempre que le deje hacer lo mismo a los demás. Si conseguimos esto sin necesidad de recurrir a la tolerancia no veo por qué no podemos prescindir de ella. Como piensa Bernard Williams, la tolerancia tal vez sea solo una virtud temporaria, un valor interino que solo tiene sentido "en ese período entre un pasado en el que nadie ha oído hablar de ella y un futuro en el que nadie la necesitará"

Por desgracia, las cosas no son tan simples para el liberalismo deontológico. Contrariamente a lo que piensa René, este tiene necesidad de la tolerancia. Y tiene necesidad de la tolerancia porque las creencias éticas de otras personas pueden ser opuestas a las creencias éticas más fundamentales de un liberal.

Como es sabido, el liberalismo exige que distingamos entre dos perspectivas distintas: la perspectiva personal y la perspectiva políti$\mathrm{ca}^{6}$. La perspectiva personal se refiere a los principios, valores y convicciones que nos orientan cuando tomamos decisiones sobre nuestra vida. Decisiones sobre, por ejemplo, qué trabajo elegir, si casarnos o no, cómo educar a nuestros hijos, o qué hacer en el tiempo libre. La perspectiva política es, en cambio, la que debemos adoptar cuando tomamos decisiones sobre asuntos públicos como el alcance de los derechos individuales, el cobro de impuestos o la distribución del ingreso.

Estas dos perspectivas perecen corresponderse con la distinción entre ética y moralidad planteada por René. Existe, sin embargo, una diferencia importante. La perspectiva personal no es puramente sin-

5 Williams, B., op cit, pág. 26.

6 Dworkin, R., Etica privada e igualitarismo politico, Barcelona, Paidos, 1993, pág. 53. 
gular. No alude simplemente a lo que consideramos bueno para nosotros, sino más bien a lo que pensamos que hace valiosa una vida en un sentido objetivo. Alguien que piensa, por ejemplo, que una vida dedicada a perseguir el éxito económico es una vida vacía, está convencido de que cualquiera que siga ese camino vive mal su vida, desperdiciando su única oportunidad de trascender o imprimir auténtico valor a su existencia. Las creencias éticas suponen siempre un juicio general por parte del agente que las sostiene; no un juicio sobre qué cosas le gustan, sino un juicio - a menudo poco elaborado- sobre la naturaleza humana y la manera en que todos deberían vivir. Incluso si alguien piensa que ninguna manera de vivir la vida es intrínsecamente mejor, asignará a esta convicción un alcance universal y verá a los que persiguen ciertas causas con pasión como criaturas que no han logrado comprender o se resisten al vacío de la existencia humana.

El desdoblamiento en las perspectivas personal y política ha sido caracterizado por muchos críticos del liberalismo como una suerte de esquizofrenia. El ciudadano liberal es, por cierto, un sujeto práctico escindido; alguien que aplica una serie de valores a su propia vida, renunciando, a la vez, a aplicarlos a uno de los ámbitos más importantes del universo normativo: el ámbito de la política. Es alguien que cree, por ejemplo, que la religión es el opio de los pueblos, pero que saldría a la calle a protestar furiosamente si su gobierno volviera ilegales las prácticas religiosas.

Esta actitud esquizofrénica que acabo de describir es la médula del liberalismo político, una de las concepciones más difundidas del liberalismo deontológico contemporáneo. Ya en su crucial artículo "Justice as fairness, political not metaphysical", Rawls explica que el liberalismo no solo debe circunscribirse al plano de lo político renunciando a proveer un orientación general para la vida, sino que además debe prescindir de una fundamentación ética general ${ }^{7}$. Solo así la justicia como equidad podría ser aceptada por las diversas doctrinas comprensivas que animan la vida cultural de una democracia

7 Rawls, J., "Justice as fairness: political not metaphysical", Philosophy \& Public Affairs, 14, 3, 1985. 
El liberalismo deontológico vuelve a la vida (y mucho antes de lo pensado)

pluralista, convertirse en el objeto de un consenso superpuesto, y funcionar como una base compartida de justificación. El hecho de que las personas acepten dar prioridad al acervo de creencias comunes sedimentadas en su concepción pública de la justicia al actuar como ciudadanos no significa, no obstante, que dejen de ver sus convicciones éticas como verdaderas. La justicia como imparcialidad no afirma ni niega ninguna doctrina compresiva razonable y no supone tampoco un compromiso con el escepticismo, el relativismo o el falibilismo. De lo contrario, sería incapaz de alcanzar sus metas constitutivas y marcharía a la bancarrota conceptual ${ }^{8}$.

Si esta rápida reconstrucción de la justicia como equidad es correcta, se ve claramente por qué el liberalismo político es perfectamente compatible con la virtud de la tolerancia. Desde esta perspectiva, un ciudadano liberal debe dejar en suspenso convicciones éticas que toma como verdaderas y plenamente operativas al momento de discutir sobre los asuntos políticos fundamentales. Consideremos, por ejemplo, el caso de un liberal político que piensa que una vida sin lugar para la religiosidad es una vida malograda. Este liberal no aspirará a que su gobierno reordene las instituciones para promover su credo. Mucho menos promoverá la persecución de ateos, herejes o infieles. Y aun así seguirá convencido de que todos deberían dar un lugar central al cultivo de la religión. De hecho, si no es un hipócrita, eso es lo que hará en su propia vida, lo que le enseñará a sus hijos y lo que recomendará a sus amigos. Sus convicciones éticas no quedan neutralizadas, suprimidas ni canceladas. Siguen en el mismo lugar en el que siempre estuvieron.

Más todavía, para el liberalismo político la tolerancia es una verdadera virtud disposicional o deliberativa más bien que una capacidad pasajera que aplicamos solo al resolver un supuesto conflicto valorativo por primera vez, como piensa René. En este sentido, la decisión de tolerar o no un comportamiento que desaprobamos dependerá de una serie de variables difíciles de sopesar en su conjunto. Supongamos que ciertos grupos políticos expresan ideas o realizan actividades

8 Rawls, J., Political Liberalism, New York, Columbia University Press, 2005, pág. 62ss. 
contrarias a la justicia como equidad. Si se trata de grupos realmente reducidos con escasa visibilidad pública y acotado margen de acción, la ciudadanía liberal podría adoptar una posición permisiva. Si, por el contrario, sus actividades representan un peligro para la estabilidad de las instituciones democráticas, quizá sería recomendable combatirlos y hasta declararlos ilegales. Del mismo modo, cuando un liberal político se pregunta si debe tolerar o no doctrinas privadas opresivas, debe considerar en qué medida sus prácticas comprometen la capacidad de sus seguidores de convertirse en ciudadanos plenamente cooperativos de la sociedad y desarrollar un compromiso con sus instituciones libres. Como consecuencia, la tolerancia no es para el liberalismo político una operación simple que se realiza una sola vez por cada creencia. Antes bien, requiere de una deliberación que sopese numerosas variables en un análisis caso por caso. Algunas de esas variables se relacionan con hechos circunstanciales, otras con contextos sociales particulares, y otras suponen una consideración de las consecuencias que diversos cursos de acción podrían producir ${ }^{9}$. Solo un verdadero phronimos, dotado de gran experiencia y capacidad para la reflexión moral, puede reconocer el justo medio entre extremos que la tolerancia representa. Acertar en este esquivo blanco no es en absoluto comparable a pasar un filtro sobre un sistema de creencias contradictorias.

A la luz de lo anterior se vuelve evidente no solamente que el liberalismo político puede acomodar perfectamente la virtud de la tolerancia, sino además que esta virtud es una parte absolutamente constitutiva de este punto de vista. Como vimos, el desdoblamiento de perspectivas liberal no surge de una renuncia a nuestras convicciones éticas más profundas, ni de un compromiso pragmático con prácticas, conductas o actos que no tenemos la capacidad de suprimir. Es, en cambio, una instanciación de la idea de respeto hacia las personas que yace en el corazón mismo del programa liberal ${ }^{10}$.

9 Kymlicka, W., Multicultural Citizenship: A Liberal Theory of Minority Rights, Oxford, Clarendon Press, 2000, pág. 167. 
El liberalismo deontológico vuelve a la vida (y mucho antes de lo pensado)

\section{El perro se muerde la cola: la tolerancia se aplica al propio liberalismo}

Ya hemos visto que el liberalismo político no solamente permite sino que además requiere la tolerancia como virtud política fundamental. Un ciudadano liberal debe renunciar a actuar, o a exigir que su gobierno actúe, en base a creencias éticas que sigue considerando plenamente verdaderas. Me gustaría ahora sugerir que algunas variantes de liberalismo deontológico, como el liberalismo político, avanzan todavía un paso más. Esperan no solo que los liberales renuncien a imponer sus concepciones éticas a los demás, sino incluso que desistan de imponerles su concepción de la moralidad política. Esta es una jugada conceptualmente sorprendente, una jugada que catapulta la tolerancia hasta un lugar que tal vez ninguna otra concepción política podría concederle.

En su breve pero inspiradora obra The Law of Peoples, Rawls aborda el problema de qué principios de justicia deberían regir una sociedad de los pueblos en el plano internacional ${ }^{11}$. Al igual que en sus trabajos anteriores, su meta no es construir una solución de compromiso que permita una convivencia estable entre sociedades que suscriben diversas concepciones de la justicia, sino ofrecer una solución de principio derivada del propio liberalismo. Para muchos liberales, la concepción de la moralidad política que el liberalismo propone es la única correcta y reclama para sí todo el campo conceptual que una teoría de la justicia puede ocupar ${ }^{12}$. Como consecuencia, o bien somos liberales y rechazamos otras maneras de ordenar las principales instituciones políticas, o bien aceptamos esas opciones alternativas, dejando en ese mismo momento de ser liberales. Pero Rawls no se suma a este club. Para él un liberal debe aplicar la tolerancia al liberalismo mismo.

Como consecuencia de este supremo ejercicio de autolimitación, la ley de los pueblos incorpora una clase ideal de sociedades que se desig-

${ }^{11}$ Rawls, J., The Law of Peoples: With "The Idea of Public Reason Revisited", Cambridge, Mass., Harvard University Press, 2001.

${ }^{12}$ Dworkin, R., A Matter of Principle, Cambridge, Mass., Harvard University Press, 1985, pág. 205. 
nan como pueblos jerárquicos decentes. Si bien estos pueblos honran algunos derechos humanos fundamentales y tratan con respeto a las minorías, no se gobiernan de modo democrático, no permiten la formación de una esfera de opinión pública libre y no reconocen a sus ciudadanos muchos de los derechos familiares en una democracia constitucional. De hecho, ni siquiera los ven como personas libres e iguales ${ }^{13}$.

Desde la publicación de la conferencia que dio origen al libro, muchos liberales han argumentado que la ley de los pueblos es una rendición incondicional, un completo abandono del pensamiento liberal. Para ellos, el valor fundamental del liberalismo es la autonomía de la persona y claudicar en su defensa supone lisa y llanamente dejar de ser libera ${ }^{14}$. El liberalismo político tendría así mucho de político y nada de liberal. Puede ser que tengan razón. Pero aun así, el argumento de Rawls representa un modo posible de articular las convicciones liberales fundamentales y permite apreciar el compromiso del liberalismo político con la tolerancia como valor supremo.

De acuerdo con Rawls, los liberales tenemos razones de principio para no imponer nuestra visión del mundo a los demás. Es este compromiso el que en el plano doméstico nos obliga a abstenernos de exigir al gobierno que promueva la autonomía privada de la gente y a fundamentar los principios de justicia sobre un liberalismo comprensivo. Como vimos, el liberalismo político articula el valor del respeto por la persona en términos de tolerancia, y la tolerancia vista en su mejor luz conduce a la neutralidad. Las variables que justifican este tránsito en una sociedad democrática son dos. La primera es la existencia de un profundo pluralismo moral, metafísico y religioso, abonado en parte por una prolongada tradición de libertades individuales. La segunda es que, a pesar de sus persistentes diferencias, la mayoría de las doctrinas comprensivas que animan la vida cultural

\footnotetext{
${ }^{13}$ Rawls, J., The Law of Peoples, págs. 63-72

${ }^{14}$ Véase, por ejemplo, Pogge, T., "An Egalitarian Law of Peoples", Philosophy \& Public Affairs, 23, 3, 1994, págs. 195-224; Buchanan, A., "Rawls's Law of Peoples: Rules for a Vanished Westphalian World", Ethics, 110, 2000, págs. 697-721; Tan, K., "Liberal Toleration in Rawls's Law of Peoples", Ethics, 108, 2, 1998, pág. 276.
} 
El liberalismo deontológico vuelve a la vida (y mucho antes de lo pensado)

de una sociedad democrática comparten un rasgo fundamental: son doctrinas razonables, es decir, doctrinas que aceptan un ordenamiento relativamente liberal de las instituciones políticas.

Pero estas variables, que hacen no solo necesario sino además posible el liberalismo político, no están presentes en todas partes. Algunas sociedades registran grandes convergencias en torno de alguna visión parcialmente comprensiva del mundo - por ejemplo, alguna visión religiosa - que puede operar como una plataforma compartida para su razón pública. Y otras carecen de una cultura pública liberal que les permita construir un consenso superpuesto sobre la justicia como equidad o alguna otra concepción liberal de la vida en sociedad.

Dadas estas importantes diferencias de contexto, Rawls piensa que el compromiso liberal con la tolerancia tiene consecuencias especiales cuando consideramos el plano internacional. En este ámbito, la tolerancia ya no requiere simplemente que renunciemos a imponerles nuestras convicciones éticas a los demás, sino que renunciemos a imponerles nuestra concepción de la moralidad política. Así lo expresa Rawls en un pasaje que, para muchos, ilumina toda su obra con una nueva luz:

...Si se esperara que todas las sociedades fueran liberales, la idea del liberalismo político no conseguiría expresar la debida tolerancia por otras formas aceptables (si, como presupongo, estas existen) de ordenar la sociedad. Nosotros reconocemos que una sociedad liberal debe respetar las doctrinas comprensivas de sus ciudadanos - religiosas, filosóficas y morales-a condición de que estas doctrinas sean perseguidas de modos compatibles con una concepción razonable de la justicia política y su razón pública. Del mismo modo decimos que, a condición de que las instituciones básicas de una sociedad no liberal cumplan con ciertas condiciones especificadas de la justicia y lo políticamente correcto y conduzcan a sus pueblos a honrar una legislación justa y razonable para la sociedad de los pueblos, un pueblo liberal debe tolerar y aceptar a dicha sociedad ${ }^{15}$.

15 Rawls, J., The Law of Peoples, pág. 59. 
Este pasaje pone en evidencia el lugar absolutamente central que la virtud de la tolerancia ocupa en el liberalismo deontológico de Rawls. Mostrar el debido respeto hacia los demás puede requerir incluso que aceptemos modos no liberales de ordenar la estructura básica de la sociedad. Del mismo modo que cuando reconocemos el derecho de otros ciudadanos a vivir de acuerdo con sus ideales no abandonamos nuestra propia visión sobre la vida humana con sentido, cuando reconocemos el derecho de ciertos pueblos no liberales a organizar sus instituciones de un modo no liberal, no dejamos de estar firmemente convencidos de que el liberalismo es la mejor concepción de la justicia política. Un liberal político que comparta las conclusiones de Rawls sobre la ley de los pueblos no creerá, por cierto, que una sociedad jerárquica con tendencias teocráticas sea más justa que una democracia constitucional con un gobierno neutral. Pero aún así, renunciará a interferir con sus modos de ser. El desdoblamiento de perspectivas se repite una vez más y el desgarramiento interno del liberal es máximo.

\section{¿Hay tolerancia sin esquizofrenia?}

Antes de concluir esta breve discusión, me gustaría sugerir que, contrariamente a lo que sostiene René, lejos de adquirir mayor protagonismo, la virtud de la tolerancia podría desdibujarse si adoptamos variantes más integradas de liberalismo. Por variantes más integradas me refiero a variantes comprensivas del liberalismo que abandonen la esquizofrenia propia del liberalismo deontológico y vean el campo de lo normativo como un territorio continuo más bien que compartimentado.

Supongamos, por ejemplo, que usted es un liberal que se niega a aceptar la distinción entre el ámbito de la ética y el de la moralidad, distinción que, según René, es un rasgo distintivo del liberalismo deontológico. O supongamos que usted es un liberal que acepta esta distinción pero concibe la moralidad como derivada de una provincia normativa más fundamental constituida por la ética. Esta es, por cierto, una perspectiva muy popular y muy intuitiva. La mayoría de nosotros tiende a pensar que no podemos opinar sobre el modo en que 
El liberalismo deontológico vuelve a la vida (y mucho antes de lo pensado)

debemos tratar a los demás o sobre cómo deberían ordenarse las principales instituciones políticas antes de saber qué es una vida humana con sentido ${ }^{16}$. De hecho, este es el camino que han seguido la mayoría de los grandes filósofos morales, incluidos Platón, Aristóteles y John Stuart Mill: un camino que nos libra de la esquizofrenia.

Si usted adhiere a este punto de vista y es un liberal, seguramente pensará que una vida humana con sentido es una vida en la que las personas viven de acuerdo a su propio plan de vida. Esta concepción general de la vida con sentido puede, a su vez, interpretarse de dos maneras distintas. Usted puede pensar, por ejemplo, que para vivir una vida con sentido basta con que la gente adopte un plan de vida como propio y pueda llevarlo a cabo sin importar que su elección sea precedida por una revisión crítica de las tradiciones en las que ha crecido. Para que este ideal se cumpla alcanza con que su sociedad impida que algunos impongan por la fuerza sus creencias a los demás y proteja a las personas que deciden abandonar sus comunidades de origen. E1 hecho de que usted sea un liberal de esta clase no implica, por supuesto, que no tenga su propia visión de qué planes de vida son mejores. Por el contrario, muy probablemente tendrá ideas firmes al respecto y tratará de vivir de acuerdo con ellas. Pero se mostrará reticente a impedir prácticas, actos o comportamientos que no coincidan con esa visión mientras no supongan coerción sobre los que las rechazan.

Alternativamente, usted puede interpretar la concepción de la vida humana con sentido que acabo de describir de un modo más exigente y pensar que solo una vida vivida de acuerdo con un plan de vida que hemos escogido luego de un escrutinio crítico vale realmente la pena. Si usted ve las cosas de esta manera tal vez se sienta más proclive a esperar que su gobierno se esfuerce por promover el espíritu crítico, combatiendo activamente aquellas doctrinas comprensivas que reclamen una adhesión dogmática. Aun así, dado que es un liberal, es muy probable que usted adopte una actitud tolerante frente a las personas que se resisten a tomar distancia del entorno cultural en el que crecieron y a examinar las creencias heredadas con objetividad científica.

${ }^{16}$ Dworkin, R., Ética Privada, pág. 59. 
Esta actitud podría fundarse en razones de principio. Así, podría suceder, por ejemplo, que al revisar con cuidado sus propias convicciones éticas, usted descubriera algún principio todavía más fundamental que proscribiera imponer sus puntos de vista a los demás. O podría suceder, en cambio, que su actitud tolerante estuviera fundada, no en razones de principio sino en razones prudenciales. Por ejemplo, usted podría no obstaculizar prácticas, actos o conductas que desaprueba porque teme que las consecuencias de no tolerarlas sean contraproducentes para su visión del mundo.

En todos estos casos, su liberalismo integrado tenderá a desdibujar el papel de la tolerancia como virtud política. Si su decisión de permitir comportamientos, actos o prácticas que desaprueba surge de sus propias convicciones éticas - ya sea porque piensa que la adopción acrítica de un plan de vida basta para vivir una vida con sentido, ya sea porque alguna creencia más fundamental proscribe la interferencia - su actitud no supondrá dejar de actuar sobre la base de sus convicciones; será, por el contrario, una exigencia derivada de su propia cosmovisión ética. Si, en cambio, su actitud se origina en la prudencia, su comportamiento no será el resultado de una disposición estable del carácter sino más bien de una imposibilidad fáctica para hacer lo que considera correcto. Su actitud tolerante no estará inspirada en la convicción de que los que piensan como usted merecen respeto y se desvanecerá no bien las cosas cambien. Al mismo tiempo, como liberal integrado, usted tenderá a ser menos tolerante en el ámbito público y se sentirá autorizado a invocar sus propias convicciones éticas al discutir sobre asuntos de justicia básica y a rechazar las invocaciones de los demás a sus propias doctrinas comprensivas. Será, para decirlo en palabras de René, mucho más proclive a la imposición de la moral.

Nada de lo anterior pretende negar, por supuesto, que la tolerancia desaparece cuando adoptamos la perspectiva integrada. Mi sugerencia es simplemente que, contrariamente a lo que René sostiene, cuando fundimos el campo de lo normativo en una única pieza, nos vemos forzados a jerarquizar creencias éticas contrapuestas hasta recuperar el equilibrio como sujetos prácticos. Solo cuando podemos distinguir entre dos ámbitos de razones distintas, experimentamos ese desgarra- 
El liberalismo deontológico vuelve a la vida (y mucho antes de lo pensado)

miento que se produce al abstenemos de actuar en base a convicciones que seguimos considerando como verdaderas. Tal vez por esta razón, muchos liberales que proponen un retorno al liberalismo comprensivo se refieren al liberalismo político de Rawls como a un liberalismo de la tolerancia ${ }^{17}$. Y tienen toda la razón: no hay dudas de que para esta perspectiva, la tolerancia es el valor político supremo.

\section{Agradecimientos}

Deseo agradecer especialmente a los editores de Discusiones por invitarme a participar de este debate, así como a René por producir con sus provocadoras ideas este interesante intercambio.

\section{Bibliografía}

Buchanan, A., "Rawls's Law of Peoples: Rules for a Vanished Westphalian World", Ethics, 110, 2000, págs. 697-721.

Dworkin, R., Ética privada e igualitarismo politico, Barcelona, Paidos, 1993.

Dworkin, R., A Matter of Principle, Cambridge, Mass., Harvard University Press, 1985.

Forst, R., "Toleration", en The Stanford Encyclopedia of Philosophy, 2012, http://plato.stanford.edu/archives/sum2012/entriesoleration/.

Gaus, G., Courtland, J. y Schmidtz, D., "Liberalism", en The Stanford Encyclopedia of Philosophy, 2015, http://plato.stanford.edu/archives/spr2015/entries/liberalism/.

Kymlicka, W., Multicultural Citizenship: A Liberal Theory of Minority Rights, Oxford, Clarendon Press, 2000.

Nicholson, P., "Toleration as a moral ideal", en Horton, J. y Mendus, S. (eds.), Aspects of Toleration, Londres/Nueva York, Routledge, 2013, págs. 158-173.

Pogge, T., "An Egalitarian Law of Peoples", Philosophy \& Public Affairs, 23, 3, 1994, págs. 195-224.

${ }^{17}$ Tan, K., Toleration, Diversity, and Global Justice, caps. 2 y 3. 
Rawls, J., The Law of Peoples: With "The Idea of Public Reason Revisited", Cambridge, Mass., Harvard University Press, 2001.

Rawls, J., Political Liberalism, New York, Columbia University Press, 2005.

Rawls, J., A Theory of Justice: Original Edition, Cambridge, Mass., Belknap Press, 2005.

Scanlon, T., The Difficulty of Tolerance: Essays in Political Philosophy, Cambridge, Cambridge University Press, 2003.

Tan, K., Toleration, Diversity, and Global Justice, Penn State Press, 2010.

Tan, K., "Liberal Toleration in Rawls's Law of Peoples", Ethics, 108, 2, 1998, págs. 276-295.

Williams B., "Toleration: an impossible virtue?" en Heyd, D., (ed.), Toleration: An Elusive Virtue, Princeton, Princeton University Press, 1998, págs. 18-27. 